\title{
THE NEW OUTLOOK IN ECOLOGY
}

\author{
By E. MI. Nicirolson, C.B. \\ Director, The Nature Conservancy
}

Ecology may be called the science of the relations of animals and plants to their environment and to one another. But this is only true if we remember that the word "animals " includes man.

We like to think of man as in a class by himself, spiritually or intellectually. But as an influence on the earth, man's role is that of an animal that has managed to multiply enormously, both in numbers and in capacity to affect other parts of nature, usually for the worse, and usually without noticing it.

We all know how rabbits can graze a hillside until it is almost bare of vegetation : man has a similar power of destroying his own habitat and, with it, that of other animals. One of the main tasks of ecology is to open our cyes to the extent and character of such processes, which do not usually happen quite fast enough to be obvious to us in our lifetime.

The very fact that I need to define ecology is an indication of something wrong with current values. Ancient civilizations, in India and China for instance, may not have known the word, but the idea was deeply understood. The questions that ecology asks and the answers that it can give are as fundamental to human thinking and behaviour now as, for example, the theory of evolution was a century ago.

Charles Elton, Director of the Bureau of Animal Population at Oxford, has described the sort of problems that ecologists are studying, and what their work can mean in terms of practical problems. He has asked whether man's divergent interests in nature-religious, xsthetic, intellectual, economic and so forth-might not perhaps be resolved by finding some wise principle of co-existence between man and nature. 'The variety of nature should, he suggests, be conserved not only because it makes for a right relation between man and living things and because it gives opportunities for richer experience, but also because it tends to promote ccological stability and what he terms ecological resistance to invaders and to explosions in natural populations.

It would be broadly true to say that discovery during the past five hundred years or so has been mainly extensive in exploring new continents and new oceans and in opening up new branches of science. Now it is becoming intensive in going deeply into the 
possibilities and limitations of life on our planet in the past, present and future, by techniques that require much more teamwork and the concerted use and blending together of what were once regarded as quite distinct sciences, such as zoology, botany and geology.

In fact ecology is not one science but a whole orchestra of sciences which are only just becoming skilful enough to perform in tune and to tackle compositions on the grand scale. The large harmonies of nature that ccology seeks to explore and to express are not merely xsthetic. They are also the harmonies of an infinitely ingenious and perfectly functioning mechanism. Nature is much more than a pleasant backcloth to the human scene. Among other things nature is a very efficient machine, but a machine that goes wrong when we throw spanners into it. It will not pay us to let this go on happening on the present scale.

That is why modern ecology is bursting out of its purely academic origins and is becoming more and more mixed up with world affairs, and in particular with economics and sociology. It is no longer visionary to look forward to our being able to grasp how nature has achieved such miracles as clothing the rocks with soil and the soil with vegetation and the vegetation with animal life. As we understand the processes we may hope to guide and at times even to control them. How revolutionary this step forward can be is evident when we recall that, even in these days of synthetics, all but an insignificant part our food and raw materials is directly derived from natural products of the past or present. The unlocking of the secrets of, say photosynthesis, could transform food and raw material prospects almost as decisively as the unlocking of the secrets of the atom has transformed the power outlook.

Ecologists, however, are far more concerned with conservation of what exists than with the incalculable possibilities of future rescarch. For example, the proportion of good productive land on the earth's surface is comparatively small and it is undoubtedly smaller than it was a thousand or even a hundred years ago, before man set about mismanaging it in a big way. Ecologists now understand pretty well how to check further losses or degradations of soil, but the process is still continuing at an alarming pace, even in Britain. 'Twice during the past decade the main line railway from King's Cross to Edinburgh has been cut by summer floods, in one case for several months. How many people realize that such incidents arise from faulty management of the watershed and that they are entirely preventable? Overburning, overgrazing and unsound drainage works on the moors, 
destroy the sponge formed by the natural vegetation and cause rainfall to run off too quickly and lead not only to floods, but to erosion and the spread of weeds like bracken.

Once we can stop deterioration we may hope to promote improvement. In some areas provision of good water would be enough to make the desert blossom, but often there is something missing in the soil, and no amount of bulldozing will make it yield crops until the deficiencies can be made good. The first step must be to find out what the deficiencies are.

One of the basic tasks of modern ecology is therefore to find out how nature works. In the first place the aim is simply to advance knowledge and to help to avoid mistakes in managing nature reserves. But even for other applied ecologists such as farmers, foresters and landscape planners, working with nature is almost invariably more sensible than not finding out how nature works and trying to compensate for that ignorance by artificial substitutes or short cuts. It might have been thought that the fiasco of the East African Ground-nut Scheme would have impressed this on all concerned, but many large and small development projects continue to be planned and executed in more or less complete ignorance of the natural context in which they are expected to function.

In order to give advice which is to be depended upon, ecologists have to get away from the laboratory and to work in field conditions, for example by experimental treatments on nature reserves. The art of managing water tables or animal populations, or the spread of different types of vegetation or the deposition or erosion of soil has been a preoccupation of men for many generations. But the science behind the art is pretty young and the application of the science is in its infancy.

Note.-The above article was part of the first of a series of talks given on the B.B.C. Third Programme, entitled "Living Heritage: The Balance of Nature". Producer, Dr. A. Clow. 